\title{
INHABILIDAD DEL DERECHO INTERNACIONAL EN CONTROVERSIAS SOCIALMENTE COMPLEJAS: CASO BOSNIA CONTRA SERBIA
}

\author{
Luis Miguel DÍAZ* \\ SUMARIO: I. Introducción. II. Qué hizo y qué no hizo la Corte. \\ III. La Corte y el derecho internacional. IV. Conclusión.
}

\section{INTRODUCCIÓN}

La sentencia de la Corte Internacional de Justicia (Corte) en el caso de Bosnia y Herzegovina contra Serbia y Montenegro, ${ }^{1}$ es representativa de la inhabilidad del derecho internacional para abordar controversias sociales complejas con sentimientos de humanidad.

La Corte no fue responsable ${ }^{2}$ de las atrocidades humanas que reconoció.

* Doctor en ciencias jurídicas (SJD) y maestro en derecho internacional (LLM) en Harvard Law School.

1 Aplicación de la Convención sobre la Prevención y Castigo del Crimen de Genocidio (Bosnia and Herzegovina v. Serbia and Montenegro). Sentencia del 26 de febrero, 2007. Consúltese en http://www.icjcij.org/docket/files/91/13685.pdf? PHPSESSID =e39$3 e 65539954 c e 40284715 a 80077 c d 9$.

2 El término responsabilidad, dependiendo del juego de lenguaje en donde sea utilizado, tiene diversos significados. Los juegos donde puede ser utilizada la palabra responsabilidad, son contextos sociales, jurídicos, morales, convencionales y personales; como el de reacciones emotivas; como equivalente a causa; como sujeción a una sanción; y como habilidad para realizar actos. Algunos de estos significados se ilustran en la historia de un capitán de barco que generalmente se encontraba borracho. "Como capitán del barco, 'X' era responsable de la seguridad de sus pasajeros, la tripulación y el barco. En el último viaje se embriagó, y resultó responsable del hundimiento del barco con todos sus ocupantes. Se pensó que estaba loco, pero los doctores lo declararon responsable de sus acciones. Durante su niñez, ninguno de sus padres fue responsable de su educación, y él como padre de familia tampoco era responsable. Varios incidentes en su carrera mostraban que no era un capitán responsable; no obstante, fue responsable ante la compañía de seguros que, finalmente resultó responsable del siniestro. Siempre sostuvo, respecto al accidente, que una tormenta era la responsable, pero que él se sentía humana y emocionalmente responsable de la tragedia. En los procedimientos legales fue declarado penalmente responsable por su conducta negligente; y en el proceso civil, se le estimó legalmente responsable por la pérdida de vidas y propiedades". Esta historia parafrasea a la de Hart, H. L. A., Punishment and Responsibility, Essays in the Philosophy of Law, Oxford, Oxford University, 1973, p. 211. 
A partir de esta apreciación se sugiere la necesidad de desaprender el enfoque jurídico para controversias internacionales socialmente complejas.

\section{QUÉ HIZO Y QUÉ NO HIZO LA CORTE}

El Gobierno de la República de Bosnia y Herzegovina presentó su caso ante la Corte. En su demanda denunciaba que Serbia y Montenegro había violado la Convención de la Prevención y Castigo del Crimen de Genocidio (la Convención) adoptada en 1948 por la Asamblea General de las Naciones Unidas. Además reclamaba una indemnización por los daños causados.

La Corte se impuso determinar si las atrocidades alegadas se habían cometido y si constituían una violación a la Convención. La Corte reconoció la existencia de asesinatos masivos en Bosnia pero no concluyó que hubiera violaciones a la Convención. Advirtió que el caso era de elevada complejidad jurídica. Era el primer caso en donde un Estado acusaba a otro del crimen de genocidio. El presidente de la Corte declaró que la Corte, al aplicar el derecho internacional, no buscó concesiones políticas ni predispuso sus conclusiones.

En una primera etapa, la Corte determinó que sí tenía jurisdicción para conocer el asunto. Esta determinación pudo haber sido cuestionada cuando la Corte reconoció que el surgimiento del nuevo Estado de Montenegro, que se había separado del Estado de Serbia y Montenegro, podría haber puesto en duda quién era realmente el Estado demandado.

La Corte reconoció que había evidencia de eventos en Bosnia y Herzegovina equivalentes a crímenes contra la humanidad pero no del crimen de genocidio en el sentido que lo define la Convención.

La Corte reconoció atrocidades contra musulmanes de Bosnia pero no encontró la intención expresa de eliminarlos como grupo, por lo que no se tipificó el crimen de genocidio.

Respecto a una serie de atrocidades contra los musulmanes de Bosnia en Srebrenica y a un grupo paramilitar denominado Scorpions que ejecutó a musulmanes de Bosnia en Trnoyo, la Corte sí encontró la intención de eliminar al grupo, pero no pudo determinar que los responsables de la masacre actuaron como órgano del Estado de Serbia y Montenegro, o por instrucciones o bajo la dirección de dicho Estado. 
Tampoco concluyó que hubiera complicidad para el crimen de genocidio. Lo que sí determinó la Corte fue que se violó la obligación de prevenir el genocidio y la de castigar a las personas responsables.

Respecto a la omisión de prevenir el crimen de genocidio, la misma Corte declaró que su declaración de dicha omisión constituía la sanción apropiada.

Respecto a la obligación de castigar a los individuos responsables, Serbia tenía y tiene la obligación de transferir a los individuos acusados de genocidio para que sean juzgados por el Tribunal Internacional para Crímenes en Yugoslavia. Este Tribunal ya había determinado que la masacre en Srebrenica era un genocidio, en la que murieron 8,000 hombres y niños.

La Corte se enfrascó en discusiones jurídicas sobre la interpretación de normas sobre jurisdicción, sobre el principio de cosa juzgada, sobre el derecho aplicable, sobre las pruebas, sobre los hechos y sobre principios generales del derecho.

La Corte concluyó que Serbia no había cometido el crimen de genocidio a través de sus órganos ni era responsable de la violación del derecho internacional consuetudinario aplicable.

La sentencia de la Corte es también una expresión en el derecho positivo de la teoría pura del derecho de Hans Kelsen. Para el autor vienés, su teoría era pura al tener como único objeto de conocimiento a la norma jurídica. ${ }^{3}$ Lo que hizo la Corte fue precisamente interpretar el derecho internacional sin prestar atención al rostro humano.

La sentencia de la Corte no ofreció fórmulas para la reconciliación social ni orientación para evitar la repetición de crímenes y asesinatos en la región.

\section{LA CORTE Y EL DERECHO INTERNACIONAL}

La Corte tiene como función decidir conforme al derecho internacional las controversias que le sean sometidas. El artículo 38 del Estatuto de la Corte establece que el derecho internacional se constituye por:

3 “Al calificarse como teoría pura, indica que entiende constituir una ciencia que tenga por único objeto el derecho (reglas de conducta y de interpretación) e ignore todo lo que no corresponda estrictamente a su definición. Principio fundamental de su método es, pues, eliminar de la ciencia del derecho todos los elementos que le son extraños". Véase Kelsen, Hans, Teoría pura del derecho, Buenos Aires, Eudeba, 1969, p. 15. 
a) Las convenciones internacionales, sean generales o particulares, que establecen reglas expresamente reconocidas por los Estados litigantes.

b) La costumbre internacional como prueba de una práctica generalmente aceptada como derecho.

c) Los principios generales de derecho reconocidos por las naciones civilizadas.

d) Las decisiones judiciales y las doctrinas de los publicistas de mayor competencia de las distintas naciones, como medio auxiliar para la determinación de las reglas de derecho.

La Corte tomó su decisión en el caso comentado con base en el artículo 38 que identifica las reglas que constituyen el derecho internacional. Estas reglas consisten en conductas obligatorias, prohibidas y permitidas, y en reglas para identificarlas e interpretarlas. ${ }^{4}$

Invito al lector a poner en duda la confianza en que la aplicación del derecho internacional para decidir controversias de conflictos sociales complejos pueda arrojar respuestas humanamente sensibles. A continuación comparto algunas razones que sustentan mi escepticismo.

\section{La normatividad y generalidad del derecho internacional}

El derecho internacional establece reglas de cómo deben ser ciertas conductas de los Estados y de los seres humanos. No reconoce cómo son o pueden ser.

El derecho internacional trata de reglas de conducta consensuadas en tratados, costumbres, principios y precedentes que obligan. La obligatoriedad de las normas jurídicas no está condicionada a cómo son o aparecen las cosas o las conductas específicas, no coteja contextos ni individualidades.

\section{Humanos inexistentes en la Corte}

La mera existencia de la Corte y los requisitos para elegir a sus miembros, presupone la ficción legal de que la Corte y sus miembros son

4 Tengo en mente el concepto de H. L. A. Hart, según el cual el derecho es un sistema de reglas primarias que establecen conductas y reglas secundarias que sirven para identificar, interpretar o modificar las reglas primarias. Hart distinguió entre las reglas del derecho positivo y la idea de un derecho natural. Véase El concepto del derecho, Buenos Aires, Abeledo-Perrot, 1968. 
independientes, y que cada miembro de la Corte ejerce sus atribuciones con toda imparcialidad.

El supuesto de la imparcialidad de los miembros de la Corte es una construcción epistemológica que existe para dar coherencia lógica al orden jurídico como un cuerpo adecuado para resolver disputas. ${ }^{5}$

Esta suposición significa que existen seres humanos que escapan a las leyes de la naturaleza, al estar inmunes o ser independientes de las influencias de los contextos donde han existido y existen. Esta presuposición es simplemente falsa y contraria a la manera de ser de todos los humanos.

La observación sobre la conducta social de los seres humanos muestra que cada humano piensa, siente y toma sus decisiones de acuerdo a su historia y expectativas. Simplemente cada cabeza crea su mundo a partir de las situaciones en las que ha vivido. Cualquier decisión de una tercera persona sobre un conflicto ajeno será siempre subjetiva y prejuiciada por la historia y expectativas personales de quien decide.

\section{La naturaleza bélica de los tribunales de derecho internacional}

Los litigios ante tribunales y los conflictos armados constituyen espacios para administrar conflictos, no para resolver los conflictos originales. Tanto en una guerra como en un litigio unos ganan y otros pierden. Ambas disciplinas comparten una estructura lógica común. Para ilustrar este punto de vista véase la equivalencia de algunos términos fundamentales:

5 La imparcialidad supuesta de los tribunales y autoridades que deciden las controversias es una herencia derivada del pensamiento filosófico-político griego, para el cual la naturaleza había creado a dos clases de seres humanos: unos nacidos para gobernar y otros para obedecer. A partir de esta creencia, Sócrates, Aristóteles y sus discípulos elaboraron tratados de organización política que ofrecían los criterios para identificar a los seres que nacieron para mandar, para hacer y ejecutar leyes, y para dirimir conflictos. Hoy, más de dos mil años después, los tribunales de derecho se sustentan en premisas similares a las de los filósofos griegos. En efecto, se presupone que debe existir una clase especial de personas para dirimir conflictos, bajo el supuesto no cuestionado de que dichas personas son diferentes a los gobernados. Ya no se presupone, como antes, que estas personas nacieron para gobernar, pero sí que son o pueden actuar con imparcialidad o de modo independiente a su subjetividad. 
- Soldado = abogado.

- Ejército = despachos de abogados.

- Declaración de guerra = demanda.

- Guerra preventiva = medidas precautorias.

- General que comande al ejército = abogado principal

- Campo de batalla = autoridades con jurisdicción.

- Dominio de reglas de ofensa y defensa = derecho procesal.

- Armamentos = deberes, derechos, facultades.

- Estrategias = instancias procesales.

- Artillería = hechos en el expediente.

- Manejo del material bélico = argumentos legales.

- Declaración de victoria = sentencia favorable.

La hermandad semántica de las palabras claves de las guerras y los litigios reflejan que tanto los abogados como los soldados son entrenados para embestir y defender, y no para manejar satisfactoriamente conflictos.

4. La expropiación de los conflictos originales por el derecho internacional

El derecho expropia los conflictos originales para convertirlos en conflictos jurídicos. Los hechos originales son objeto de una metamorfosis que los descontextualiza y convierte en espacios donde compiten jerarquías normativas e interpretaciones jurídicas.

\section{La prohibición de la comunicación en el derecho internacional}

El derecho en mayor o menor grado prohíbe la comunicación humana. Impide el contacto personal entre los que deciden, los que acusan, los que defienden, los expertos, los que asesoran y los afectados por las decisiones, al suponer que dicha comunicación puede contaminar la pureza del proceso y la imparcialidad de los protagonistas. Así, las reglas procesales impiden observar y escuchar al rostro humano, y con ello fomentan un anonimato que genera agresividad. 


\section{Lo impropio de las reglas del derecho internacional}

El caso presentaba y presenta dinámicas variadas con numerosas causas y efectos en largos periodos, pero la Corte lo enfocó como si tuviera una dimensión simple de derecho-obligación o de causa-efecto.

El caso tenía y tiene una orientación desconocida hacia el futuro en oposición a un futuro predecible, pero la Corte sólo examinó sucesos pasados con base en reglas preestablecidas y omitió elaborar escenarios futuros.

El caso se refería y refiere a conflictos tanto en contra de autoridades, como entre autoridades, así como entre actores sociales que toman sinnúmero de formas, pero la Corte se limitó a identificar a autoridades.

El caso representaba y representa la coexistencia de distintos sistemas de valores y autoridades en contraposición a un sistema dogmático y con una autoridad exclusiva, pero la Corte decidió, cumpliendo con su propio Estatuto, con base en un exclusivo sistema de valores.

Por las razones anteriores, la estrategia utilizada por la Corte para decidir controversias sociales complejas con base en reglas preestablecidas fue notoriamente inadecuada.

\section{CONCLUSIÓN}

La Corte al estar encadenada por sus propias reglas de existencia, por sus funciones y por sus reglas para operar, sólo pudo entregar a la comunidad internacional un pronunciamiento que escarnece sentimientos humanos.

Un problema social complejo como el caso entre Bosnia y Serbia requiere no de un tribunal de derecho, sino de un enfoque sistemático, novedoso, flexible y participativo que se oriente a reducir el papel del derecho y del Estado, y que propicie espacios para soluciones negociadas. 